\title{
Context-dependent success of restoration of a key species, biodiversity and community composition
}

\author{
Judi E. Hewitt*, Vonda J. Cummings \\ National Institute of Water and Atmosphere Research, PO Box 11-115, Hamilton, New Zealand
}

\begin{abstract}
Increasingly, restoration is seen as a management and conservation tool, with aims of restoring not just a single species but a natural functioning community. In marine soft sediment systems, biodiversity and communities are often strongly related to the presence of key species, suggesting that restoration of a single species could result in restoration of communities/biodiversity. The success of such a restoration is likely to be context-dependent, driven by hydrodynamics, local diversity and ambient communities. A transplant experiment with adult Austrovenus stutchburyi was conducted in 2 different hydrodynamic compartments of a large New Zealand harbour. After $1 \mathrm{yr}$, densities of transplant sized individuals and smaller adults were enhanced at both sites, although enhancement of juveniles only occurred at 1 site. Measures of diversity did not increase in the experimental plots; however, at 1 site the benthic macrofaunal community had changed. Probable reasons for the location-dependent results are differences in hydrodynamic connectivity and ambient communities, although density-dependent effects driven by small differences in the success of adult enhancement may also have been important.
\end{abstract}

KEY WORDS: Restoration · Biodiversity $\cdot$ Shellfish $\cdot$ Benthos $\cdot$ Communities $\cdot$ Intertidal $\cdot$ Dispersal

\section{INTRODUCTION}

In the face of increased species extractions, species invasions and environmental degradation, many agencies include restoration in their management and conservation efforts (Dobson et al. 1997, Rice et al. 2000, Hobbs 2009). Restoration goals occur at all levels, from that of restoring a single species in a specific location, through to enhancing biodiversity and improving ecological functioning. Marine efforts often focus on single species (e.g. Bergen et al. 2000, van Katwijk et al. 2009), and especially species that are commercially, recreationally or culturally important (e.g. shellfish; Rice et al. 2000, Fegley et al. 2009). Increasingly, however, ecosystem-based management focuses on the need to decrease habitat destruction (e.g. Cogan et al. 2009, Thrush \& Dayton 2010), while conservation efforts focus on habitat restoration (e.g. Bell et al. 2001, Miller \& Hobbs 2007) with the assumption that habitat improvement increases species richness and density (the 'field of dreams' hypothesis; Palmer et al. 1997). In many systems, biodiversity is often strongly related to the presence of a key species, which, through its influence on the local habitat, modifies the system such that it becomes more (or less) suitable for other species to live within. Marine 'foundation species' include flora and fauna such as kelp, cordgrass, corals, sponges, gorgonians, tube worm mats and large bivalves (e.g. Cummings et al. 1998, Levin et al. 1998, Fowler-Walker \& Connell 2002, Levin \& Dayton 2009). In soft-sediment systems especially, foundation species may (for example) alter boundary flow conditions, sediment stability, provide substrate for settlement and, as a consequence, form a biogenic habitat with an asso- 
ciated community composition and biodiversity. Given their influence on biological and physical characteristics of their environment, restoration of communities/biodiversity could, thus, be achieved by restoring a foundation species, and with it, the associated assemblage.

In any restoration study, maintenance of the restored area, species or habitat is important. If invaders have been removed, do they reinvade? If species have been transplanted, do the transplanted organisms form a viable long-term population/community? Details of the specific modes and scales of dispersal are important not only in answering these questions, but also in determining whether biodiversity in general can be restored (Roughgarden et al. 1985, Hanski \& Gilpin 1997, Hewitt et al. 2009). For example, in marine systems, animals may be brooders or broadcasters, but may also undergo dispersal as juveniles and/or adults. The potential for ontogenetic shifts in habitat requirements (Beukema 1973, Rowe \& Chisnall 1996, Stewart \& Creese 2002) is also important as this may result in movement of the target species away from the restored area at a later stage of development.

In marine systems, dispersal cannot be considered in isolation from hydrodynamic conditions. Interactions between dispersal scales and modes and hydrodynamics may isolate locations from each other (Lundquist et al. 2004), restricting the potential for metapopulation development (Palumbi 2003) and the colonisation of other organisms into a restored area. It may also mean that larvae produced by transplanted animals do not remain at the site. On the seafloor, smaller scale hydrodynamic differences in benthic boundary layers can be generated by restored species or ambient communities (Eckman \& Nowell 1984, Noji \& Noji 1991) affecting the potential for emigration or immigration. In addition, substrate type at the site to be restored may also affect the influence that the transplanted species has on the surrounding community (e.g. Commito \& Boncavage 1989, Valentine \& Heck 1993, Cummings et al. 1998). All these factors can generate site-specific or 'context-dependent' results.

If restoration of a single species is designed to increase biodiversity or restore a fully functioning community, context-dependent results become even more likely. Immigration of colonists not only depends on their dispersal modes, hydrodynamic connectivity and benthic boundary layer conditions but also on meta-community dynamics, and potential species interactions with the ambient community within and surrounding the restored area.
The present study assesses the effectiveness of an attempt to restore biodiversity through increasing the abundance of a foundation species, the cockle Austrovenus stutchburyi, on 2 intertidal sandflats in a large New Zealand harbour. A. stutchburyi is common throughout New Zealand, where it is the subject of an important commercial and recreational fishery. It is a surface bioturbator which forms dense patchy beds and has been demonstrated to increase macroinvertebrate species richness, affect macroinvertebrate community composition, increase sediment deposition and change nutrient fluxes both within the sediment and between the sediment and the overlying water (Thrush et al. 2006, de Juan \& Hewitt 2011). Reproductively viable adults were transplanted to 2 sandflats with differing benthic invertebrate assemblage compositions, hydrodynamic conditions (exposed vs. semi-enclosed embayment) and hydrodynamic connectivity to the main body of the harbour (Lundquist et al. 2009). Our hypothesis was that restoration success would be context dependent, related to differences between the sites in terms of surrounding benthic species and hydrodynamics, although we realised that with only 2 sites we would not be able to isolate the factors causing any context dependency. We assessed restoration success in terms of: (1) maintenance of densities and physiological condition of transplanted adult A. stutchburyi, (2) enhancement of densities of all size classes of A. stutchburyi, (3) enhancement of benthic macrofaunal species richness and diversity, and most importantly (4) divergence of benthic macrofaunal community composition in the experimental areas from that of the control areas.

\section{MATERIALS AND METHODS}

\section{Study species}

Austrovenus stutchburyi is an infaunal bivalve common on intertidal flats around New Zealand. It has a life span of $>5 \mathrm{yr}$, and grows up to $60 \mathrm{~mm}$ (shell length). Spawning generally occurs in summer, although spawning individuals are frequently found at other times of the year (J. E. Hewitt unpubl. data). A. stutchburyi broadcast larvae into the water column, but dispersal of post settlement life stages, both in the water column and with bedload movement, is common (Pridmore et al. 1991, Hewitt et al. 1996, Hewitt et al. 1997, Cummings et al. 2007), and adults are known to crawl $>1 \mathrm{~m}$ per tidal cycle (Hewitt et al. 1997). Adults and juveniles generally inhabit the 
same areas, although adults are more numerous and faster growing further down the shore (Dobbinson et al. 1989, Stewart $\&$ Creese 2002). While A. stutchburyi burrow only 1 to $3 \mathrm{~cm}$ into the sediment, the heavy shell of adult-sized individuals provides some protection from bird and eagle ray predation; a previous transplant study observed no evidence of predation on uncaged adults (Cummings et al. 2007).

Many New Zealand intertidal macrofauna undergo post settlement dispersal as juveniles or adults. Recruitment is generally at least once per year with generation times ranging from 6 mo to $>5$ yr. While seasonality is strong, recruitment for all species does not occur in a single season, although less recruitment usually occurs in winter.

\section{Study sites}

The study was conducted at low-mid tide on 2 intertidal sandflats in Whangarei Harbour, North Island, New Zealand. The 2 sites, Takahiwai (adjacent to a site where cockle reseeding trials were previously conducted; Cummings et al. 2007) and Parua Bay, are situated on opposite sides of the harbour (Fig. 1A), approximately $4 \mathrm{~km}$ apart, with different exposure to waves and hydrodynamic connectivity to the main body of the harbour (Lundquist et al. 2009). Takahiwai is a wide exposed sandflat located alongside the main channel of the harbour, while Parua is a semi-enclosed embayment (Fig. 1A). Substrates at the 2 sites consist predominantly of fine sands $(>84 \%)$, although Parua sediments also contained mud $(12 \%)$, which was negligible at Takahiwai $(<1 \%)$. Both sites previously supported cultural harvesting, but prior to the 1980s densities decreased; an effect attributed to dredge spoil dumping and discharges from a cement works, both of which have now ceased. Macrobenthic communities at both sites were dominated by a small deposit-feeding bivalve, Nucula hartvigiana, although Takahiwai had high numbers of crustaceans while Parua had high numbers of polychaetes (pers. obs. on a site selection visit and confirmed by sampling in this study).

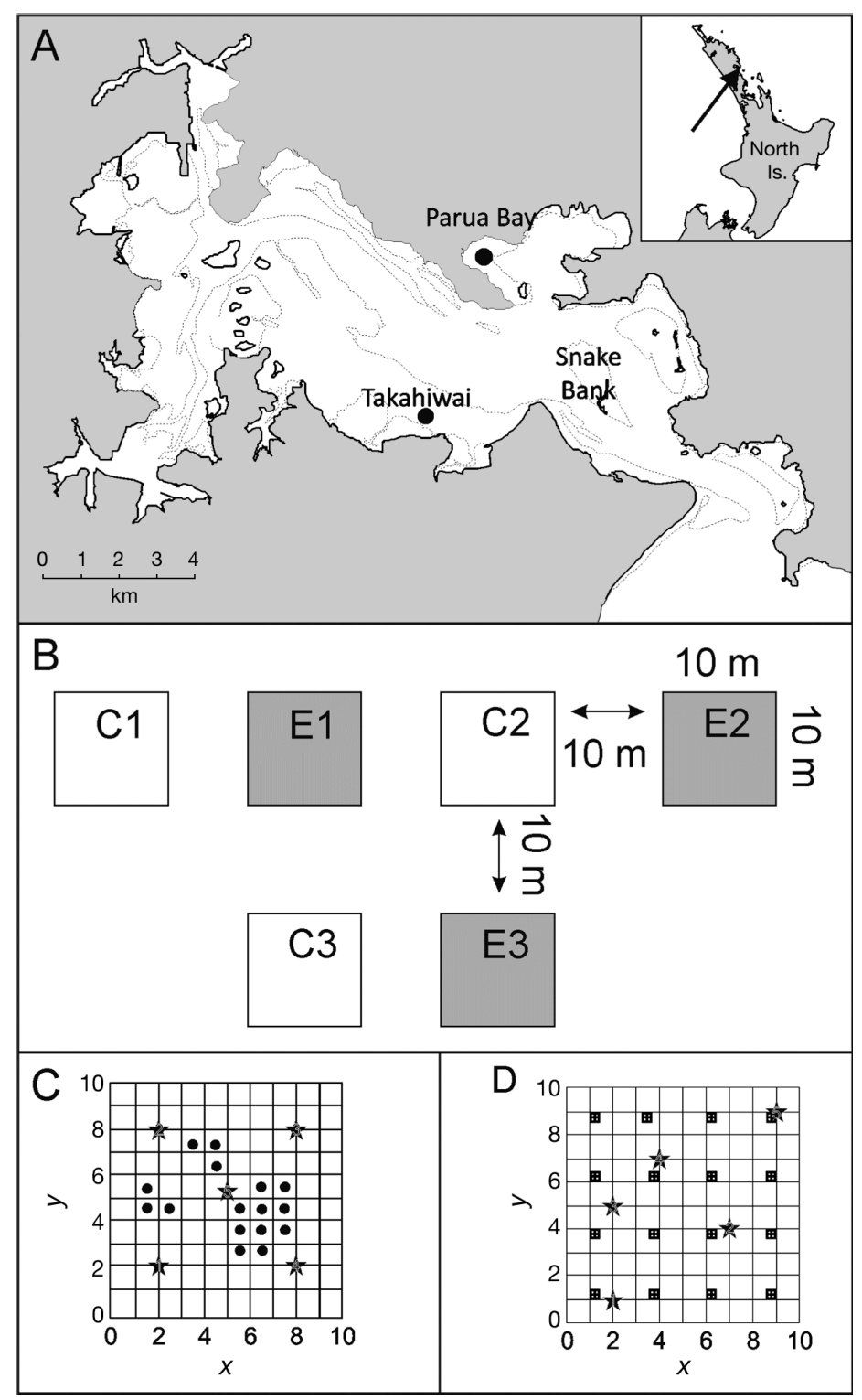

Fig. 1. (A) Location of study sites, (B) arrangement of Experimental ' $\mathrm{E}$ ' and Control ' $\mathrm{C}$ ' areas on the sandflats, (C) location of transplant plots (black dots) and initial sampling of macrofaunal and sediment cores (stars) and (D) endpoint sampling of $30 \times 30 \mathrm{~cm}$ quadrats (squares) and macrofauna and sediment core samples (stars)

\section{Experimental setup}

At each site, 3 replicate blocks consisting of paired Control and Experimental areas, each $10 \times 10 \mathrm{~m}$ and separated by $\geq 10 \mathrm{~m}$, were established over a $30 \times$ $70 \mathrm{~m}$ area of sandflat (Fig. 1B) in October 2006. The Control and Experimental pairs from each block were at the same tidal height, but Block 3 was located slightly higher on the shore than Blocks 1 and 
2 (Fig. 1B). Within each of the Experimental areas, sixteen $60 \times 60 \mathrm{~cm}$ transplant plots were nested in a heterogeneous array (Fig. 1C), chosen to reflect the natural distribution and mobility of Austrovenus stutchburyi on sandflats (Hewitt et al. 1996, Cummings et al. 2007). In each plot, 180 individuals (25 to $32 \mathrm{~mm}$ ) were transplanted (i.e. 2880 individuals per $10 \times 10 \mathrm{~m}$ Experimental area). Individuals transplanted at each site had been collected the previous day from an area of naturally high densities (Snake Bank, Fig. 1A), sized and kept in aerated seawater overnight.

Prior to the transplantation, macrofaunal community composition $(>500 \mu \mathrm{m})$ was determined from 5 core samples (15 cm diameter, $10 \mathrm{~cm}$ deep) taken in each treatment replicate located as in Fig. 1C. Paired surface sediment cores $(2.6 \mathrm{~cm}$ diameter, $1 \mathrm{~cm}$ deep) were taken adjacent to these cores, to characterise sediment chlorophyll a ( $\mathrm{chl} a)$, organic content and particle size.

\section{Bivalve recruitment}

Core samples were collected in January, February, March and May of 2007 to monitor potential colonisation by juveniles (new recruits and post settlement stages). On each date, 10 core samples ( $5 \mathrm{~cm}$ in diameter, $2 \mathrm{~cm}$ deep) were collected from each plot, with cores not collected from within $2 \mathrm{~m}$ of the location of a sample collected in previous months. Preliminary assessment of data from all 4 sampling dates showed that the major recruitment of bivalve colonists occurred in March 2007; consequently, only this data is presented and analysed here.

\section{Final sampling}

In October 2007, 12 mo after setup, all areas were sampled to assess sediment characteristics, macrofaunal abundance and cockle densities. Macrofaunal abundance and sediment characteristics were assessed at 5 locations within each area, as described for the initial (October 2006) sampling (Fig. 1D). To determine the densities and sizes of Austrovenus stutchburyi, sixteen $30 \times 30 \mathrm{~cm}$ quadrats were excavated within each area (Fig. 1D), and numbers in each of the 4 size classes were counted $(4-10 \mathrm{~mm}$, 10-25 mm, 25-32 mm, >32 mm). However, no individuals $>32 \mathrm{~mm}$ and only a few $<10 \mathrm{~mm}$ were observed.

\section{Condition}

Physiological condition was assessed at each site, and the donor site, in October 2007. Five individuals were collected from each Control and Experimental area at Takahiwai and Parua, and 20 from Snake Bank. Physiological condition was determined based on a dry flesh weight to dry shell weight ratio; dry weights were determined by drying at $60^{\circ} \mathrm{C}$ to constant weight.

\section{Sample processing}

Macrofauna cores were sieved (500 $\mu \mathrm{m}$ mesh), preserved in $70 \%$ isopropyl alcohol and stained with rose bengal before being sorted, identified to the lowest practical taxonomic level (generally species) and counted. Individuals of Austrovenus stutchburyi $<1,1-4,4-10$ and $>10 \mathrm{~mm}$ were counted separately. Cores collected to assess bivalve colonists were sieved on a $180 \mu \mathrm{m}$ sieve and preserved as above, before enumeration of post larval $(<1 \mathrm{~mm})$ and juvenile (1 to $4 \mathrm{~mm}$ ) stages of $A$. stutchburyi.

Sediment cores were frozen and stored in the dark until analysis. Sediment for chl a analysis was freeze dried and chl a was then extracted from sediments using $95 \%$ ethanol. The extract was processed using a spectrophotometer, with an acidification step used to separate degradation products (phaeophytin) from chl a (Sartory 1982). Sediment particle size was determined by digesting the sediments in $6 \%$ hydrogen peroxide for $48 \mathrm{~h}$ to remove organic matter and disperse small particles. The samples were then wet sieved on $2 \mathrm{~mm}, 0.5 \mathrm{~mm}, 0.250 \mathrm{~mm}$ and $0.063 \mathrm{~mm}$ mesh sieves before drying all fractions to constant weight at $60^{\circ} \mathrm{C}$. Percentage fractions (by weight) of coarse, medium and fine sand and mud fractions were then calculated. Organic content, measured as loss on ignition (LOI), was determined by drying the sediment at $60^{\circ} \mathrm{C}$ until a constant weight was reached, then combusting in a muffle furnace for $5.5 \mathrm{~h}$ at $400^{\circ} \mathrm{C}$.

\section{Statistical analyses}

A number of analyses were conducted to assess the success of transplanting on Austrovenus stutchburyi densities. Most analyses were based on 3-way generalised linear models (GzLM), with appropriate error structures and log-link functions, using Treatment (Control, Experiment) and Site (Takahiwai, 
Parua) as fixed factors and Block (1 to 3) as a random factor (using the lmer routine in Rv.2.15.1, $\mathrm{R}$ Development Core Team 2012). Sites were included as fixed factors because of differences in hydrodynamic conditions and background densities and sizes of adults.

Survival, dispersal and condition of transplanted Austrovenus stutchburyi

The success of transplanting was tested using the 3-way GzLM model (with Poisson error structure). Differences in physiological condition of adults from the Control and Experiment areas at each site were also tested using the 3-way GzLM model (with normal error structure). Movement of Austrovenus stutchburyi from their initial transplant position was assessed using a 3-way GzLM (with a Poisson error structure and a log-link function), this time using position (inside, $<1 \mathrm{~m}$, and $>1 \mathrm{~m}$ from an initial transplant plot) and Site as fixed factors and Block as a random factor.

Effect of transplants on conspecific juveniles

Densities of newly settled $(<1 \mathrm{~mm})$ and post settlement (1 to $4 \mathrm{~mm}$ ) Austrovenus stutchburyi collected in the small cores from the March 2007 recruitment period were compared using the 3-way GzLM model (Poisson error structure and a log-link function). Densities of post settlement A. stutchburyi (4 to $10 \mathrm{~mm}$ ) from macrofauna cores in October 2007 were too low for valid statistical comparisons (max. 3 individuals per site). Densities of older (10 to $25 \mathrm{~mm}$ ) individuals recovered from the $30 \times 30 \mathrm{~cm}$ quadrats in October 2007 were analysed using the 3-way GzLM model (with Poisson error structure).

Effects on community composition and biodiversity

A combination of multivariate and univariate analyses were used to compare characteristics of macrofaunal communities and their biodiversity observed in the Experimental and Control areas. Univariate analyses were conducted on number of taxa, number of individuals, Pielou's evenness and ShannonWiener diversity. For the multivariate analyses, ordination by non-metric multidimensional scaling (MDS), PERMANOVA and SIMPER (Primer E;
Anderson 2001, Clarke \& Gorley 2006) were conducted on Bray-Curtis similarities of square-root transformed data.

A 2-way analysis (GzLM or PERMANOVA) was used to determine whether any spatial differences between Control and Experimental areas existed prior to the transplants. As there were no significant differences, we then tested whether there were differences post-transplant using the 3-way model (GzLM or PERMANOVA again with Block as a random factor).

Effects on sediment characteristics

Sediment chl $a$, organic content, mud and fine sand concentrations in Control and Experimental plots were compared before and after the transplants (October 2006 and 2007) separately, using the 3-way GzLM model (with normal error structures).

\section{RESULTS}

\section{Survival, distribution and condition of transplanted Austrovenus stutchburyi}

One year after transplanting (October 2007), approximately twice as many transplant sized individuals were found in the Experimental areas than in the Control areas at both sites $(\mathrm{p}<0.0001$, Table S1 in the supplement at www.int-res.com/articles/suppl/ m479p063_supp.pdf), indicating the transplants had been successful. Average Experimental area densities were slightly higher at Parua than at Takahiwai (5.2 cf. 4.3 ind $0.09 \mathrm{~m}^{-2}$ ). Interestingly, at both sites in October 2007, the density of transplant sized Austrovenus stutchburyi differed depending on the position of the block on the sandflat, with more individuals retrieved from the Experimental area situated slightly higher on the shore (i.e. 25 to $30 \%$ more individuals in Block 3, see Fig. 1B). This pattern applied regardless of the spatial patterns observed across the sandflats in the Control areas. Significantly higher abundances of transplant sized Austrovenus stutchburyi were found closer to the original transplant plot locations, and within the original transplant plots at both sites $(p<0.0001$, Table S1), with stronger differences between abundances observed within the original transplant plots and greater than $1 \mathrm{~m}$ away at Parua than Takahiwai (Fig. 2, Table S2 in the supplement at www.int-res. com/articles/suppl/m479p063_supp.pdf). 
Physiological condition was similar at the 3 sites, and no differences between individuals found in the Control or Experimental areas at Takahiwai or Parua were detected $(p>0.5$ for both the treatment and the site $\times$ treatment interaction term).

\section{Effect of transplants on conspecific juveniles}

Transplants did not significantly enhance densities of Austrovenus stutchburyi new recruits $(<1 \mathrm{~mm})$ during the March 2007 recruitment, when similar numbers were found in the Experimental and Control areas at both sites (Fig. 3, p = 0.7500, Table S3 in the supplement at www.int-res.com/articles/suppl/ m479p063_supp.pdf). There were, however, higher densities of new recruits at Parua (Fig. 3, p < 0.0001). No effects were found on the densities of juvenile $A$. stutchburyi (1 to $4 \mathrm{~mm}$ ) collected in March 2007 at either site (Fig. 3; interaction term and treatment term both $\mathrm{p}>0.5$, Table S3).

High numbers of young (10 to $25 \mathrm{~mm}$ ) Austrovenus stutchburyi were found in the quadrats in October 2007 at both sites with higher numbers observed in Experimental plots (Fig. 3, Table S1). Although a significant Site $\times$ Treatment interaction term was observed ( $p=0.0009$, Table S1), this was due to the stronger effect observed at Takahiwai $(p<0.0001)$ than at Parua $(\mathrm{p}=0.0306)$.
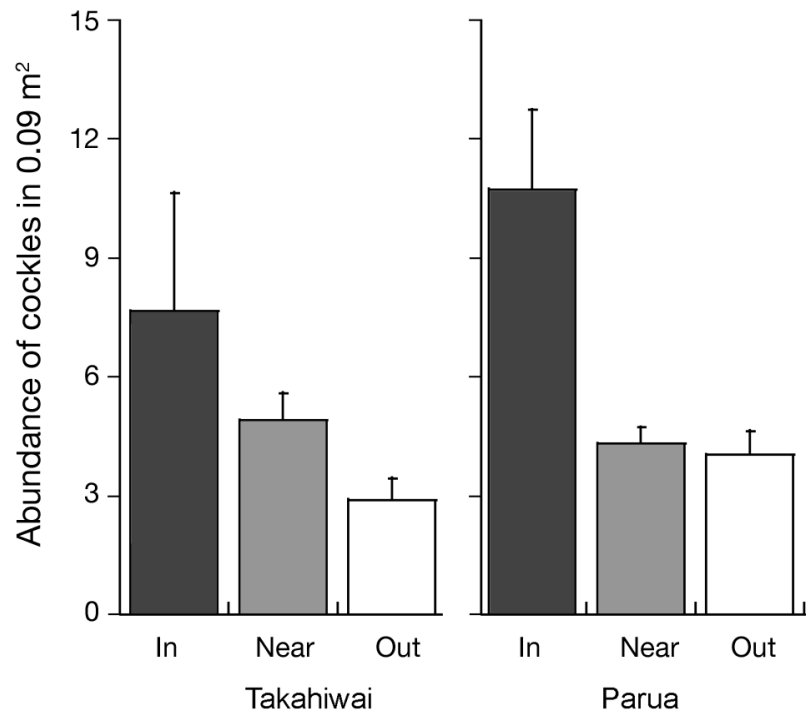

Fig. 2. Austrovenus stutchburyi. Average (+SE) abundance of adult cockles $(25-32 \mathrm{~mm})$ found in Experimental areas $1 \mathrm{yr}$ after transplanting, either within original transplanted plots (In), within $1 \mathrm{~m}$ of original transplant plots (Near), or $>1 \mathrm{~m}$ from original transplant plots (Out)

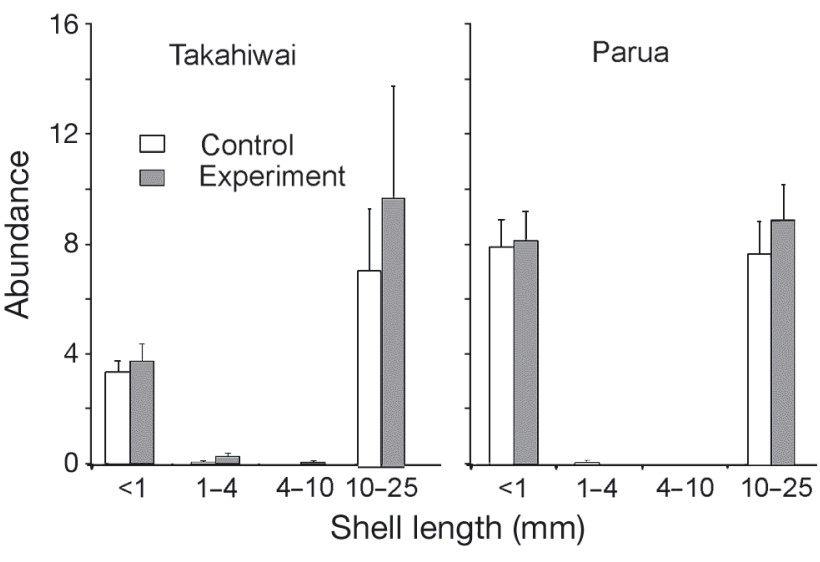

Fig. 3. Austrovenus stutchburyi . Average abundance (+SE) of different size classes of cockles. Sizes $\leq 10 \mathrm{~mm}$ were from small cores collected in March 2007 (abundance $0.002 \mathrm{~m}^{-2}$ ), while sizes $>10 \mathrm{~mm}$ were collected from $0.09 \mathrm{~m}^{2}$ quadrats in October 2007

\section{Effects on biodiversity and community composition}

Although no differences in diversity indices between treatments at each site were observed at the start of the experiment ( $p>0.40)$, there were differences between sites, with Takahiwai having greater average diversity (i.e. total number of species, evenness and Shannon-Wiener diversity indices Fig. 4). On the final sampling date (October 2007), differences between sites were still observed (Fig. 4, Table S4 in the supplement at www.int-res.com/ articles/suppl/m479p063_supp.pdf). There were no consistent differences in diversity as a result of transplanting across both sites (Fig. 4, Table S4). Site $\times$ Treatment interactions were observed for total number of individuals and number of species ( $p=0.0085$ and $\mathrm{p}=0.0104$, respectively, Table S4). Numbers of individuals were significantly higher in the Control areas at Takahiwai, $\mathrm{p}=0.011$ ). There were no differences between Control and Treatment areas at either site that were significant at $\mathrm{p}=0.05$.

Prior to establishment of the transplants in October 2006, the macrofaunal communities at both Parua and Takahiwai were dominated by the small bivalve Nucula hartvigiana (43 and 18 ind. core $^{-1}$, respectively). At each site, the community compositions in the Control and Experimental areas were similar, as indicated by the overlap shown in the MDS ordination plot and test statistics (Site $\times$ Treatment interaction term Pseudo $F=1.0659, \mathrm{p}=0.4125$, treatment pseudo $F=1.341$, p = 0.193, Fig. 5). At Takahiwai, there was a clear spatial pattern, with the communities from the block higher on the shore (Block 3) situated to the far left of the plot relative to those from 

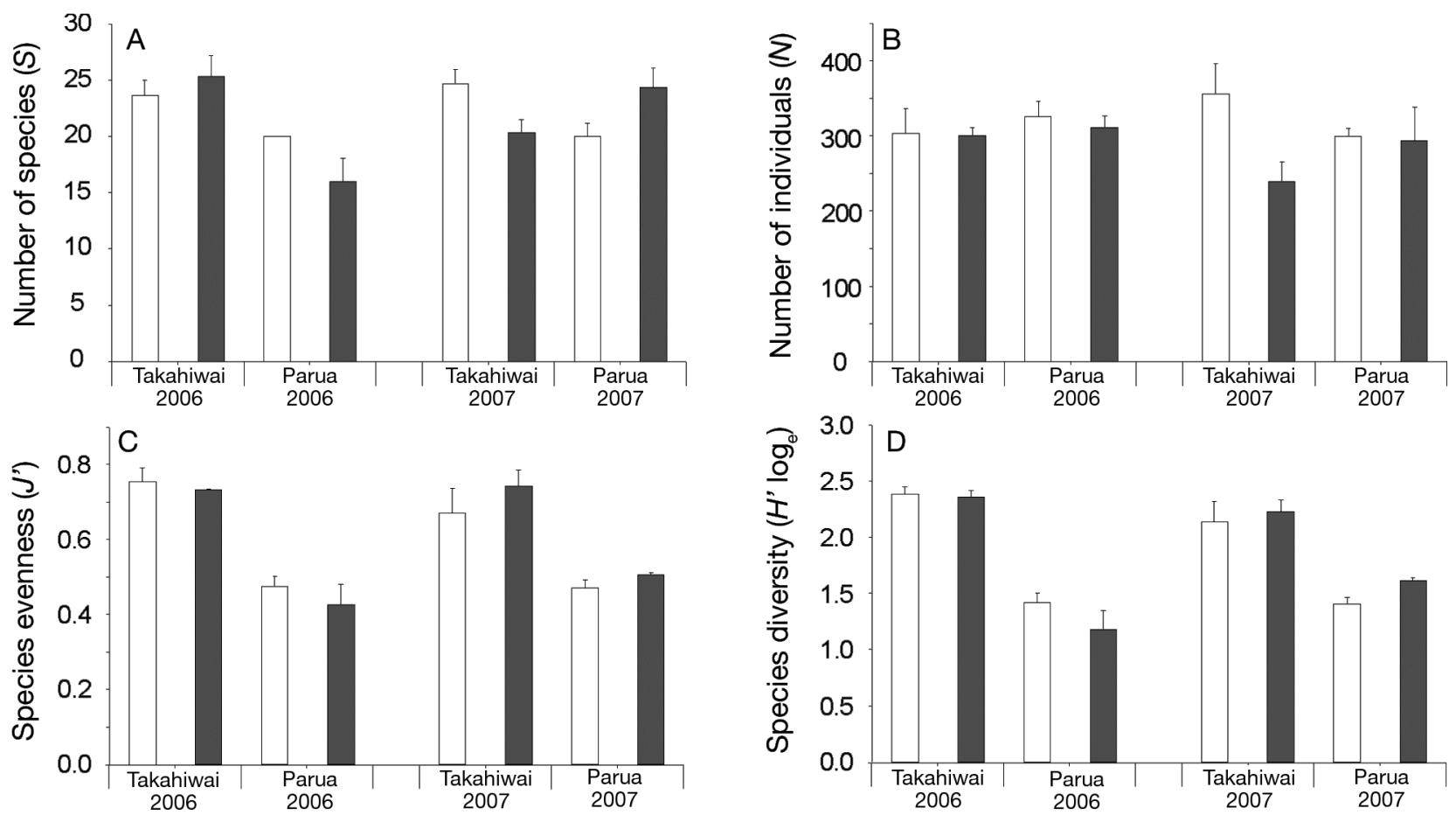

Fig. 4. Austrovenus stutchburyi. (A) Number of species, (B) number of individuals, (C) species evenness and (D) species diversity found in the macrofauna cores taken in October 2006 and 2007 at Takahiwai and Parua between Control (white) and

Experimental areas (shaded)

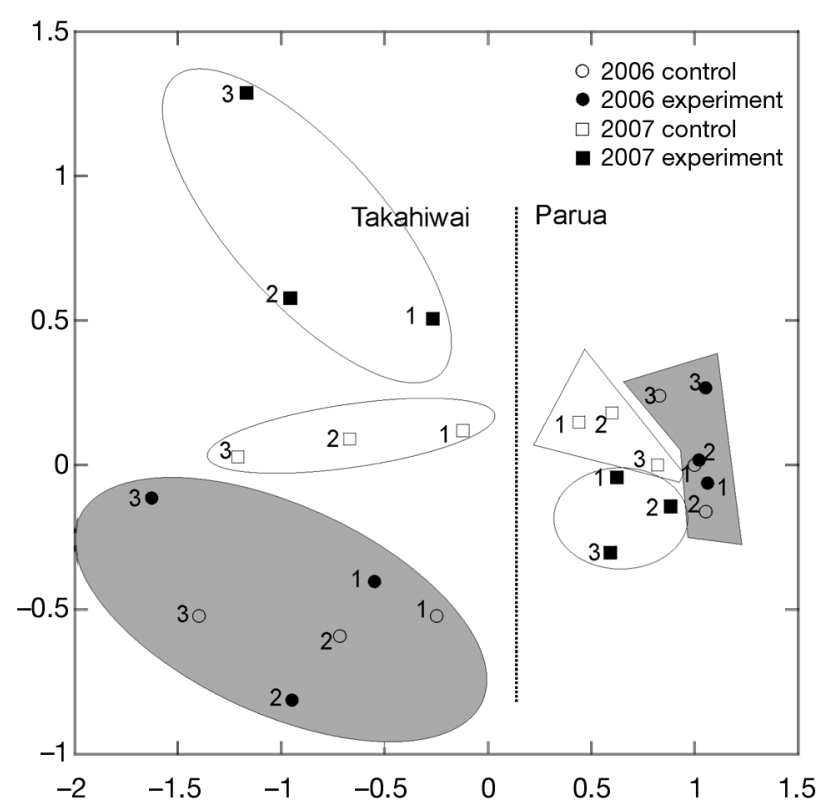

Fig. 5. Austrovenus stutchburyi. Non-metric multidimensional scaling ordination of macrofaunal community composition found at Takahiwai and Parua in 2006 (circles) and 2007 (squares), including block (shore position) information. Shaded areas contain the 2006 data, unshaded areas the 2007 data the other blocks. The Takahiwai and Parua macrofaunal communities were clearly separated in ordination space (pseudo $F=57.621, \mathrm{p}=0.001$ ), with much more variation observed at Takahiwai (Fig. 5). At Takahiwai, crustaceans (Colurostylis lemurum, Waitangi brevirostris and Corophidae), polychaetes (Syllinae, Exogoninae and Orbinia papillosa) and bivalves (Macomona liliana and Felaniella zelandica) were common (>2 ind. $0.018 \mathrm{~m}^{-2}$ core). Polychaetes (Heteromastus filiformis and Macroclymenella stewartensis) and Macomona liliana were amongst the most common species found at Parua. Austrovenus stutchburyi occurred in low abundance at Parua (>1 ind. $0.018 \mathrm{~m}^{-2}$ core), although these were considerably smaller in size than the transplanted individuals, but not at Takahiwai.

In October 2007, Nucula hartvigiana was still the dominant taxa in the Control and Experimental areas at both sites, with Macomona liliana the second most common species. Some separation of the treatments had occurred (Fig. 5). Differences in community composition between the Experimental and Control area did not occur at both sites (Pseudo $F=5.99, \mathrm{p}=0.001$ ) with a significant difference occurring at Takahiwai $(t=3.131, \mathrm{p}=0.001)$, but not at Parua $(t=1.248, \mathrm{p}=$ 
0.07). M. liliana was an important contributor to the differences between Control and Experimental areas at both sites, with higher abundances in the control areas (9 cf. 4 individuals, respectively, for Parua; 17 cf. 10 individuals, respectively, at Takahiwai). At Takahiwai, abundances of $N$. hartvigiana (22 cf. 14 individuals), Colurostylis lemurum (6 cf. 2 individuals), Orbinia papillosa (3 cf. 1 individual) and Syllinae ( 7 cf. 3 individuals) were more abundant in the Control areas, while the polychaete, Scoloplos cylindrifer, was more common in the Experimental areas (4 cf. $<1$ individual).

\section{Effects on sediment characteristics}

Sediments at both Takahiwai and Parua comprised predominantly fine sand (>84\%). There were no differences in sediment characteristics between Control and Experimental areas at either site prior to the transplants ( $p>0.20$ for all comparisons). While significant Site $\times$ Treatment interaction terms were observed for chl $a$ and fine sand content (Table S5 in the supplement at www.int-res.com/articles/suppl/ m479p063_supp.pdf), individual contrast statements did not reveal any within-site control treatment comparisons significant at the 0.10 level, suggesting that sediment characteristics had not changed as a result of our experimental transplants.

\section{DISCUSSION}

Our transplants successfully enhanced the densities of transplant sized Austrovenus stutchburyi for over 12 mo at both sites. Transplanting did not affect physiological condition, nor did it result in a change in sediment characteristics at either site. However, despite this success, settlement of early A. stutchburyi recruits $(<1 \mathrm{~mm})$ was not enhanced, nor were post settlement individuals sized 1 to $4 \mathrm{~mm}$. Effects of post settlement individuals sized 10 to $25 \mathrm{~mm}$ were more variable, although increases were observed at both sites, there were larger effects at Takahiwai. The effect of the transplants on community structure and biodiversity was not consistent, supporting our hypothesis of context-dependent success.

There was some difference between sites in the degree to which our transplants enhanced the density of adult Austrovenus stutchburyi, with slightly higher abundances found in the Experimental areas at Parua than at Takahiwai. However, at both sites, higher numbers of adults were recovered from within, or $<1 \mathrm{~m}$ from, the location of the original transplant plots. Thus, few individuals had moved away from the transplant plots (Parua Bay $<4 \%$, Takahiwai $27 \%$ ). This is in contrast to our previous, smaller-scale reseeding trials conducted at Takahiwai (Cummings et al. 2007), which recorded 50\% loss of transplanted individuals due to movement of adults. Overall, it seems that the transplant plot arrangement successfully mimicked the natural patchy distribution of $A$. stutchburyi across these sandflats. Interestingly, our results also suggested aggregative movement towards our high density patches of adults by 10 to $25 \mathrm{~mm}$ individuals. This may indicate that our transplant patch densities could have been higher, but also suggests that highdensity aggregations of large adults confer individual benefits to these mid-sized individuals (as reflected by the positive numeric response).

We also found some evidence of differences in either survival or movement based on tidal height, with 25 to $30 \%$ more transplant sized individuals found in the Experimental area highest up the shore (Block 3). This was unexpected as the difference in tidal height and subsequent immersion time relative to the other Experimental areas was relatively small ( $\sim 5 \mathrm{~cm}$ out of a tidal range of 2 to $4 \mathrm{~m}$ and $\sim 30 \mathrm{~min}$ less submergence time). Tidal height is known to affect Austrovenus stutchburyi condition and growth rates, both of which are enhanced at low shore levels (Stewart \& Creese 2002).

To clearly demonstrate the success of our restoration, we had hoped to observe enhanced settlement of Austrovenus stutchburyi. Densities of 1 to $4 \mathrm{~mm}$ juveniles and settlement of new recruits $(<1 \mathrm{~mm})$ were not enhanced at either site. The latter is consistent with results of a previous manipulation experiment studying adult-juvenile interactions, which demonstrated that $A$. stutchburyi adults did not enhance settlement of new $(<1 \mathrm{~mm})$ recruits (Thrush et al. 1996a). Our initial hypothesis was that any sitedependency of juvenile settlement would be driven by differences in the availability of recruits. Limited larval dispersal is increasingly documented in marine and estuarine systems, (e.g. Sponaugle et al. 2002, Cowen et al. 2003, Lundquist et al. 2004) and patchy population distributions of many species suggest that hydrographical barriers and the connectivity of a restored location to the metapopulation will be particularly important to long-term restoration success (e.g. Fegley et al. 2009). A companion study investigated possible sources of larval recruits in Whangarei Harbour by modelling dispersal of larvae and probable settling sites under a number of hydro- 
dynamic conditions and release points (Lundquist et al. 2009). This demonstrated that larvae released from the dense commercial cockle beds near the mouth of the harbour (including our donor site, Snake Bank) would preferentially be transported outside the harbour, but that both of our study sites should receive equal proportions of any larvae that remained. In addition, any larvae produced at Takahiwai and Parua should largely be retained at these respective sites (Lundquist et al. 2009). The latter potentially explains why the abundances of $<1 \mathrm{~mm}$ recruits were twice as high at the Parua site, as ambient densities of adults were also higher there than at the Takahiwai site (Fig. 2).

The transplants significantly altered overall community composition at Takahiwai only. Although with only 2 sites we cannot isolate the contributing factors with any certainty, consideration of the species involved suggests that pre-transplant community composition was important. Many of the observed changes were consistent with those found in a study examining the effect of removing Austrovenus stutchburyi on benthic communities and ecosystem function in Whitford estuary by Thrush et al. (2006). More Macomona liliana were found in the Control areas at both of our sites and in A. stutchburyiexcluded plots in Whitford, and more Nucula hartvigiana and Orbinia papillosa were found in the Control areas at Takahiwai and in A. stutchburyiexcluded plots in Whitford. The consistency between our results and those of Thrush et al. (2006) suggests that the Takahiwai Experimental areas are tracking towards those of a 'natural' A. stutchburyi community. The species driving the change at Takahiwai are largely absent from Parua Bay, and this may explain the lack of community response at this site. Differences in response may also be driven by the presence of a large tube-dweller (Macroclymenella stewartensis) amongst the numerical dominants at Parua. Tube worms could be expected to affect the benthic boundary layer potentially enhancing deposition of colonists and preventing settled individuals from dispersing (Woodin 1976, Cummings et al. 1996, Thrush et al. 1996b).

Strong effects of our transplants on biodiversity were not observed 12 mo later. This is despite the fact that higher average and total taxon richness is generally observed in beds of Austrovenus stutchburyi relative to beds of another common infaunal bivalve, Macomona liliana, or to sandflats without large structuring organisms (de Juan \& Hewitt 2011). However, in this multi-estuary analysis, de Juan \& Hewitt (2011) also noted differences in the relationship between beds of A. stutchburyi and taxon richness dependent on the degree of habitat fragmentation within an estuary. Estuaries with many small patches were less likely to show increased richness in A. stutchburyi beds; thus, the size of the patches we used in this study, together with the landscape patch structure throughout Whangarei Harbour, may limit the degree to which small-scale $A$. stutchburyi restorations can increase macrofaunal richness. The length of time since transplantation (Heleno et al. 2010), and the timing of the restoration event (Fegley et al. 2009) relative to reproduction recruitment and important environmental factors (e.g. rainfall, temperature; Cummings et al. 2007, Meyer et al. 2010) may also be important.

In a recent review of the state of Austrovenus stutchburyi bed restoration in New Zealand, Marsden \& Adkins (2010) considered the transfer of adults as the most promising technique available, but highlighted the need to establish the ability of transplanted individuals to grow, reproduce and establish new populations. In the present study, we show that the transplanted patches and the physiological condition (and thus reproductive potential) of the transplanted individuals were maintained after 12 mo. Larvae were likely being produced and, although we did not detect recruitment of new recruits $(<1 \mathrm{~mm})$ into the patches of transplanted adults, enhancement of juveniles ( 1 to $4 \mathrm{~mm}$ ) and of larger 10 to $25 \mathrm{~mm}$ individuals occurred at one and both sites, respectively. Furthermore, the hydrodynamic conditions at each site were such that the small individuals $(<4 \mathrm{~mm})$ would be retained in the area, indicating the potential for the wider population to be self-sustaining.

However, our study reveals other important factors to be considered when deciding to undertake restoration, especially when the intent is to restore biodiversity and a natural functioning community through the enhancement of a foundation species. Maintenance of natural patchiness is likely to be important, especially if negative or positive intra- or interspecific interactions occur. Establishing whether such interactions are likely to be density-dependent is also important; for example, we found a significant enhancement of Austrovenus stutchburyi sized 1 to $4 \mathrm{~mm}$ in the experimental areas at the site where actual enhancement had been slightly lower. Most important, we think, is the consideration that success is likely to be context-dependent, driven by landscape factors such as site connectivity and habitat fragmentation, and local-scale features such as within-site community composition and richness. 
The effect of site connectivity will be a balance between the ability to retain larvae or post-settlers, while still remaining connected to the regional species pool so that other species can colonise. Studies on fragmentation suggest that large patches throughout the dispersal landscape help maintain species richness, possibly by providing a greater pool of nearby colonists. Our results suggest that the number of species present at the transplant site can have contrasting effects. A naturally lower number of species pre-transplant gives more scope for increases to occur/be detected, especially if space is a constraint. At the same time, a higher number of species in the surrounding community increases the probability that species that naturally co-occur with the foundation species can colonise or increase in density. Finally, the presence of other foundation species has the highest potential of introducing confounding effects (e.g. Angelini et al. 2011).

Acknowledgements. Many thanks to the Kaitiaki Roopu of the Whangarei Harbour and G. MacKay and S. Hailes (NIWA) for their significant contribution and commitment to these reseeding trials. The field component of this study was funded by the Northland Regional Council's Whangarei Harbour Health Improvement Fund (Northport) and the New Zealand Foundation for Research, Science and Technology programmes: Restoration of Aquatic Ecosystems (CO1X0305) and Effective Management of Marine Biodiversity and Biosecurity (CO1X0502). Thanks also to the reviewers and the editor for their constructive comments, which resulted in an improved manuscript.

\section{LITERATURE CITED}

Anderson MJ (2001) A new method for non-parametric multivariate analysis of variance. Austral Ecol 26:32-46

Angelini C, Altieri AH, Silliman BR, Bertness MD (2011) Interactions among foundation species and their consequences for community organization, biodiversity, and conservation. BioScience 61:782-789

Bell SS, Brook RA, Robbins BD, Fonseca MS, Hall MO (2001) Faunal response to fragmentation in seagrass habitats: implications for seagrass conservation. Biol Conserv 100: 115-123

Bergen A, Alderson C, Bergfors R, Aquila C, Matsil MA (2000) Restoration of a Spartina alterniflora salt marsh following a fuel oil spill, New York City, NY. Wetlands Ecol Manag 8:185-195

Beukema JJ (1973) Migration and secondary spatfall of Macoma balthica (L.) in the western part of the Wadden Sea. Neth J Zool 23:356-357

Clarke RT, Gorley RN (2006) Primer v6. PrimerE, Plymouth

Cogan CB, Todd BJ, Lawton P, Noji TT (2009) The role of marine habitat mapping in ecosystem-based management. ICES J Mar Sci 66:2033-2042

Commito JA, Boncavage EM (1989) Suspension-feeders and coexisting infauna: an enhancement counterexample. J Exp Mar Biol Ecol 125:33-42
Cowen RK, Paris CB, Olson DB, Fortuna JL (2003) The role of long distance dispersal versus local retention in replenishing marine populations. Gulf Caribb Res 14: 129-137

$>$ Cummings VJ, Pridmore RD, Thrush SF, Hewitt JE (1996) The effect of the spionid polychaete Boccardia syrtis on the distribution and survival of juvenile Macomona liliana (Bivalvia: Tellinacea). Mar Biol 126:91-98

> Cummings VJ, Thrush SF, Hewitt JE, Turner SJ (1998) The influence of the pinnid bivalve Atrina zelandica (Gray) on benthic macroinvertebrate communities in softsediment habitats. J Exp Mar Biol Ecol 228:227-240

Cummings VJ, Hewitt JE, Halliday J, MacKay G (2007) Optimizing the success of Austrovenus stutchburyi restoration: preliminary investigations in a New Zealand estuary. J Shellfish Res 26:89-100

de Juan S, Hewitt J (2011) Relative importance of local biotic and environmental factors versus regional factors in driving macrobenthic species richness in intertidal areas. Mar Ecol Prog Ser 423:117-129

Dobbinson SJ, Barker MF, Jillett JB (1989) Experimental shore level transplantation of the New Zealand cockle Chione stutchburyi. J Shellfish Res 8:197-212

> Dobson A, Bradshaw AD, Baker AJ (1997) Hopes for the future: restoration ecology and conservation biology. Science 277:515-522

> Eckman JE, Nowell AR (1984) Boundary skin friction and sediment transport about an animal-tube mimic. Sedimentology 31:851-862

Fegley SR, Peterson CH, Geraldi NR, Gaskill DW (2009) Enhancing the potential for population recovery: restoration options for Bay Scallop populations, Argopectin irradians concetricus, in North Carolina. J Shellfish Res 28: 477-489

> Fowler-Walker MJ, Connell SD (2002) Opposing states of subtidal habitat across temperate Australia: consistency and predictability in kelp canopy-benthic associations. Mar Ecol Prog Ser 240:49-56

Hanski IA, Gilpin ME (1997) Metapopulation biologyecology, genetics, and evolution. Academic Press, San Diego, CA

Heleno R, Lacerda I, Ramos JA, Memmott J (2010) Evaluation of restoration effectiveness: community response to the removal of alien plants. Ecol Appl 20:1191-1203

> Hewitt JE, Thrush SF, Cummings VJ, Pridmore RD (1996) Matching patterns with processes: predicting the effect of size and mobility on the spatial distributions of the bivalves Macomona liliana and Austrovenus stutchburyi. Mar Ecol Prog Ser 135:57-67

> Hewitt JE, Pridmore RD, Thrush SF, Cummings VJ (1997) Assessing the short-term stability of spatial patterns of macrobenthos in a dynamic estuarine system. Limnol Oceanogr 42:282-288

Hewitt JE, Thrush SF, Lundquist C (2009) Scale-dependence in ecological systems. In: Encyclopedia of life. John Wiley \& Sons, Chichester. Available at www.els. net/WileyCDA/ElsArticle/refId-a0021903.html

> Hobbs R (2009) Woodland restoration in Scotland: ecology, history, culture, economics, politics and change. J Environ Manag 90:2857-2865

> Levin LA, Dayton PK (2009) Ecological theory and continental margins: where shallow meets deep. Trends Ecol Evol 24:606-617

Levin LA, Talley TS, Hewitt JE (1998) Macrobenthos of Spartina foliosa (Pacific Cordgrass) salt marshes in 
Southern California: community structure and comparison to a Pacific mudflat and a Spartina alterniflora (Atlantic Smooth Cordgrass) marsh. Estuaries 21:129-144

Lundquist CJ, Thrush SF, Oldman JW, Senior AK (2004) Limited transport and recolonization potential in shallow tidal estuaries. Limnol Oceanogr 49:386-395

Lundquist C, Oldman JW, Lewis MJ (2009) Predicting suitability of cockle restoration sites using hydrodynamic models of larval dispersal. NZ J Mar Freshw Res 43: 735-748

Marsden ID, Adkins SC (2010) Current status of cockle bed restoration in New Zealand. Aquacult Int 18:83-97

- Meyer CK, Whiles MR, Baer SG (2010) Plant community recovery following restoration in temporally variable riparian wetlands. Restor Ecol 18:52-64

Miller JR, Hobbs RJ (2007) Habitat restoration-do we know what we're doing? Restor Ecol 15:382-390

Noji CIM, Noji TT (1991) Tube lawns of spionid polychaetes and their significance for recolonization of disturbed benthic substrates. A review. Meeresforschung 33: 235-246

Palmer MA, Ambrose RF, Poff NL (1997) Ecological theory and community restoration ecology. Restor Ecol 5: 291-300

Palumbi SR (2003) Population genetics, demographic connectivity, and the design of marine reserves. Ecol Appl Suppl 13:S146-S158

Pridmore RD, Thrush SF, Wilcock RJ, Smith TJ, Hewitt JE, Cummings VJ (1991) Effect of the organochlorine pesticide technical chlordane on the population structure of suspension and deposit feeding bivalves. Mar Ecol Prog Ser 76:261-271

R Development Core Team (2012) R: a language and environment for statistical computing. R Foundation for Statistical Computing, Vienna. Available at www.r-project.org

Rice M, Valliere A, Caporelli A (2000) A review of shellfish restoration and management projects in Rhode Island. J Shellfish Res 19:401-408

Roughgarden J, Iwasa Y, Baxter C (1985) Demographic theory for an open marine population with space-limited recruitment. Ecology 66:54-67

Editorial responsibility: Lisandro Benedetti-Cecchi, Pisa, Italy
Rowe DK, Chisnall BL (1996) Ontogenetic habitat shifts by Galaxias gracilis (Galaxiidae) between the littoral and limnetic zones of Lake Kanono, New Zealand. Environ Biol Fishes 46:255-264

Sartory DP (1982) Spectrophotometric analysis of chlorophyll $a$ in freshwater phytoplankton. Technical Report TR 115. Hydrological Research Institute, Pretoria

Sponaugle S, Cowen RK, Shanks A, Morgan SG and others (2002) Predicting selfrecruitment in marine populations: biophysical correlates and mechanisms. Bull Mar Sci 70: 341-375

Stewart MJ, Creese RG (2002) Transplants of intertidal shellfish for enhancement of depleted populations: preliminary trials with the New Zealand little neck clam. J Shellfish Res 21:21-27

Thrush SF, Dayton P (2010) What can ecology contribute to ecosystem-based management of marine fisheries? Annu Rev Mar Sci 2:419-441

Thrush SF, Hewitt JE, Pridmore RD, Cummings VJ (1996a) Adult/juvenile interactions of infaunal bivalves: contrasting outcomes in different habitats. Mar Ecol Prog Ser 132:83-92

> Thrush SF, Whitlatch RB, Pridmore RD, Hewitt JE, Cummings VJ, Maskery M (1996b) Scale-dependent recolonization: the role of sediment stability in a dynamic sandflat habitat. Ecology 77:2472-2487

> Thrush SF, Hewitt JE, Gibb M, Lundquist C, Norkko A (2006) Functional role of large organisms in intertidal communities: community effects and ecosystem function. Ecosystems 9:1029-1040

Valentine JF, Heck KL (1993) Mussels in seagrass meadows: their influence on macroinvertebrate abundance and secondary production in the northern Gulf of Mexico. Mar Ecol Prog Ser 96:63-74

van Katwijk MM, Bos AR, de Jonge VN, Hanssen LSAM, Hermus DCR, de Jong DJ (2009) Guidelines for seagrass restoration: importance of habitat selection and donor population, spreading of risks, and ecosystem engineering effects. Mar Pollut Bull 58:179-188

Woodin SA (1976) Adult-larval interactions in dense faunal assemblages: patterns of abundance. J Mar Res 34:25-41

Submitted: March 26, 2012; Accepted: November 30, 2012

Proofs received from author(s): March 26, 2013 